\title{
Eu acho é muito amor: $O$ ano em que o Eu Acho é Pouco se vestiu de Bajado
} I think it's too much love: the year that 'Eu Acho É Pouco' dressed as Bajado

\author{
Rafael Santana \& Eva Rolim Miranda
}

memória gráfica, linguagem gráfica, design da informação, carnaval.

\begin{abstract}
Este artigo toma como unidade de análise uma estampa carnavalesca desenvolvida pela agremiação brasileira Eu Acho é Pouco em homenagem ao artista popular Bajado (1912-1993). Considerando o objeto de estudo um artefato da cultura material, este estudo em memória gráfica utilizou ferramentas do design da informação para a análise visual. Constatou-se que o discurso gráfico sintetizou figurativamente as duas grandezas semânticas e as articulou em pesos hierárquicos equânimes favorecendo um protagonismo solidário entre elas. O procedimento metodológico seguiu os seguintes passos: (1) levantamento historiográfico; (2) definição das ferramentas orientadoras da análise; (3) análise do artefato visual: produção e linguagem gráfica; (4) inferências sobre a significação.
\end{abstract}

graphic memory, graphic language, information design, carnival.

This article takes as a unit of analysis a carnival print developed by the Brazilian association Eu Acho é Pouco in tribute to the popular artist Bajado (1912-1993). As a visual artifact belonging to material culture, this graphic memory study was based on the visual analysis tools of information design. It was found that the graphic discourse figuratively synthesized the two semantic greats and articulated them in equal hierarchical weights favoring a protagonism of solidarity between them. The methodological procedure followed the following steps: (1) historiographic survey; (2) definition of tools to guide the analysis; (3) visual artifact analysis: production and graphic language; (4) inferences about signification.

\section{Notas introdutórias}

Este trabalho é parte da pesquisa em desenvolvimento no programa de pós-graduação em design da Universidade Federal de Pernambuco que estuda o artista plástico brasileiro Bajado (1912 - 1996). Considerado um pintor naï ${ }^{1}$, sabe-se que ele também atuou como artista gráfico na criação de painéis comerciais, charges, quadrinhos, embalagens de pão, cartazes de cinema etc. No campo pessoal, foi amante e brincante do carnaval de rua, fato que justifica a recorrência da temática carnavalesca em seus trabalhos de cavalete. Dentre as quarenta pinturas que compõem o corpus de análise da dissertação, mais de trinta foram concebidas durante a década de 1970, ou seja, no período 'mais repressivo' (Fausto, 2015, p. 267) da ditadura civil militar.

No livro Eu Acho é Pouco: o carnaval em vermelho e amarelo (Veras, 2019) encontra-se uma coleção de trinta e seis composições gráficas que estamparam as camisas dos carnavais passados. Uma delas, a de 1993 (figura 1), foi idealizada em homenagem a Bajado pelo seu octogésimo aniversário. Neste sentido, compreendendo que o artefato foi concebido para agregar os valores do Eu Acho é Pouco e ao mesmo tempo evocar a personalidade de Bajado, o objetivo desta pesquisa é compreender como o artefato gráfico sintetizou essas duas grandezas semânticas por intermédio da linguagem visual.

Considerando a estampa do Eu Acho é Pouco como um artefato visual de teor político, afetivo e simbólico, ou seja, como um objeto de notável dimensão híbrida e por se tratar de uma única peça, não optamos pela elaboração de uma ficha de análise tradicional. Por outro lado, utilizamos ferramentas teóricas do design da informação como forma de nortear nossa

\footnotetext{
${ }^{1}$ Artistas autodidatas que não aprenderam o ofício na academia ou qualquer instituição de ensino artístico. Suas referências são notadamente de origem popular e historicamente se manifestaram marginalmente ao refinamento plástico dos acadêmicos de belas artes.

Anais do 9 CIDI e 9 CONGIC

Luciane Maria Fadel, Carla Spinillo, Anderson Horta,

Cristina Portugal (orgs.)

Sociedade Brasileira de Design da Informação - SBDI

Belo Horizonte | Brasil | 2019

ISBN 978-85-212-1728-2

Proceedings of the 9th CIDI and 9th CONGIC

Luciane Maria Fadel, Carla Spinillo, Anderson Horta,

Cristina Portugal (orgs.)

Sociedade Brasileira de Design da Informação - SBDI

Belo Horizonte | Brazil | 2019

ISBN 978-85-212-1728-2
} 
análise visual. Exposto desta forma, nosso direcionamento metodológico seguiu as seguintes etapas: (1) levantamento historiográfico em livros e acervos públicos; (2) definição das ferramentas orientadoras da análise; (3) análise do artefato visual: produção e linguagem gráfica; (4) inferências sobre a significação: síntese do trabalho.

Figura 1: Estampa em homenagem a Bajado (Fonte: Veras, 2019)

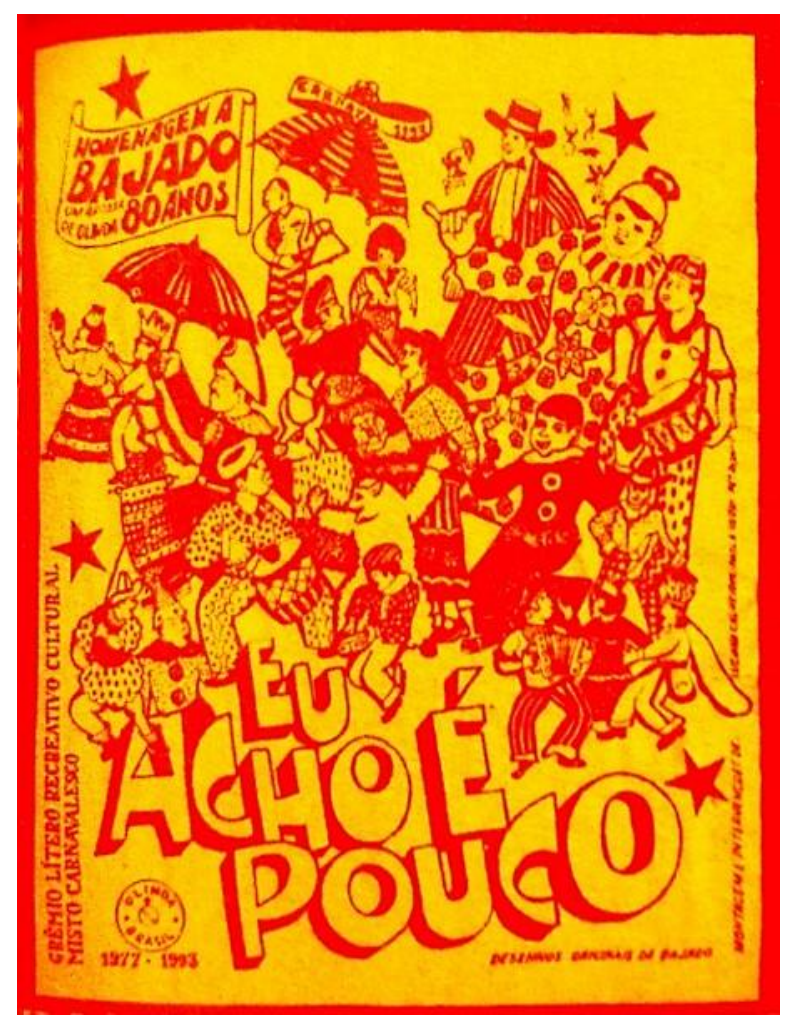

\section{Memória gráfica e cultura material}

Farias (2018, pp. 10-28) afirma que os estudos em memória gráfica buscam 'compreender a importância e o valor de artefatos visuais, em particular impressos efêmeros, na criação de um sentido de identidade local'. As vistas que os trabalhos desenvolvidos atualmente evidenciam diversas formas de abordar o tema, a autora pontua alguns caminhos: cultura visual, cultura impressa (ou da impressão), cultura material, história do design gráfico e memória coletiva.

Pelo interesse na 'produção material de contextos geográficos/sociais ou históricos', nas 'técnicas utilizadas na produção', nas 'atividades em que são usados/percebidos, os modos como afetam as pessoas, intermediando costumes, relações sociais, e conferindo significação às atividades humanas' (Lima et al., 2016, p. 205), a tipologia com a qual nossa pesquisa mais se aproxima é a da memória gráfica associada à cultura visual e à cultura material.

Embora pareçam 'coisas' separadas, para Meneses (2003, p. 25) 'a cultura material - da qual, a rigor, a cultura visual poderia ser considerada uma subcategoria', deve ser estudada considerando tanto o contexto material e social como também os aspectos físicos, empíricos, corporais e sensoriais da produção/reprodução social. Para este autor, 'o uso do termo "cultura" aqui também pressuporia mediação de significados e valores' (Ibidem).

É importante reforçar que na prática a distinção entre as dimensões físicas, corporais e ideacionais da cultura material não existe, sendo grandezas, portanto, inseparáveis. Sobre isso, Woodward (2007, pp. 14-15) afirma que 'os objetos são culturalmente poderosos porque, na prática, eles conectam manipulação física e mental' (tradução nossa). No âmbito das pesquisas sobre cultura material, segundo Farias (2018, p.25), 'um método-chave para deduzir Anais do 9ํㅡㄹ Congresso Internacional de Design da Informação | CIDI 2019 Proceedings of the 9th Information Design International Conference 
uma história a partir de "coisas gráficas" é a análise da linguagem gráfica e visual' (retomaremos este ponto na seção 4).

\section{Carnaval é política}

Cinco anos antes de fundar o Língua Ferina, vulto primário do que se tornaria o Eu Acho é Pouco, Ivaldevan Calheiros foi mantido em cárcere político por dezesseis dias (figura 2). $\mathrm{O}$ ano era 1972 e o Brasil, governado pelo general Médici, vivia os efeitos do 'milagre econômico' (1969-1973). Segundo Fausto (2015, p. 268), o plano econômico de Delfim Neto combinou um 'extraordinário crescimento econômico com taxas relativamente baixas de inflação', por outro lado, promoveu o acúmulo de renda para as classes alta e média ao passo que reduziu o salário dos trabalhadores menos qualificados. O Brasil era reconhecido mundialmente pelo contraste entre o alto potencial industrial e os baixíssimos índices de qualidade de vida da população (ibidem).

Figura 2: Primeira página do interrogatório de Ivaldevan Calheiros (Fonte: Secretaria da segurança pública, 1972).

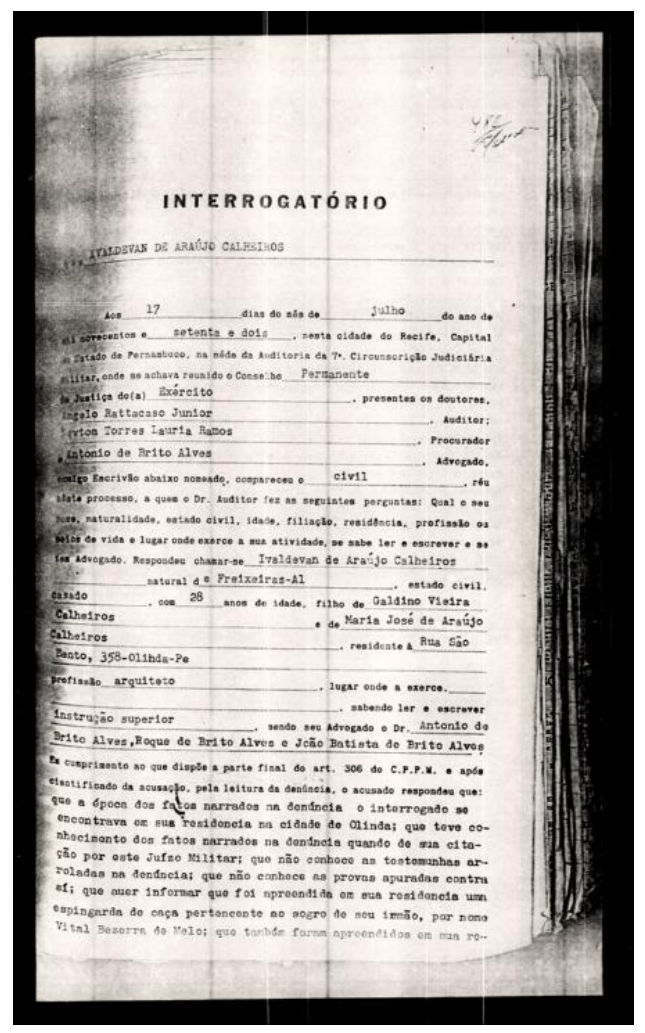

Conforme consta nos autos de apreensão, entre os vários objetos que evidenciavam sua subversão (para os parâmetros da ditadura) estavam livros, panfletos e '(40) quarenta cartazes PROPAGANDA COMUNISTA' (Secretaria da segurança pública, 1972, s. p.). Segundo Ivaldevan,

não se pode dissociar a política do Eu Acho é Pouco. Tem que ter as duas coisas juntas. Na realidade, embora tenham pessoas que não participaram da luta contra a ditadura, grande parte estava envolvida. Foram agregadas pelo movimento (Calheiros, 2019, p. 25).

O nascimento do bloco entre 1975-1976, remonta ao período da 'reabertura política' (19741988). Marcado incialmente pelas investidas do presidente Ernesto Geisel em transformar gradativamente o sistema ditatorial em uma 'democracia conservadora' e muito embora o Al-5 só tenha entrado em extinção em 1979, o período de reabertura seguiu com a intensificação da censura, das torturas e dos 'sumiços' (Fausto, 2015). 
Não se sabe ao certo se a primeira saída do 'Língua Ferina' se deu em 1975 ou 1976, anos do emblemático caso envolvendo o diretor de jornalismo da TV Cultura de São Paulo, Vladimir Herzog (1937-1975). No entanto, é certo que no ano de 1977 o Eu Acho é Pouco fez seu primeiro cortejo (Veras, 2019). O primeiro estandarte foi criado por Roberto Lúcio (integrante do grupo de amigos fundadores) a partir de recortes de jornal. Somente em 1978 apareceram o vermelho e o amarelo na comunicação da agremiação (Calheiros, 2019).

Figura 3: Recorte de uma das primeiras menções ao Eu Acho é Pouco (Fonte: Diário de Pernambuco, acervo da biblioteca nacional).

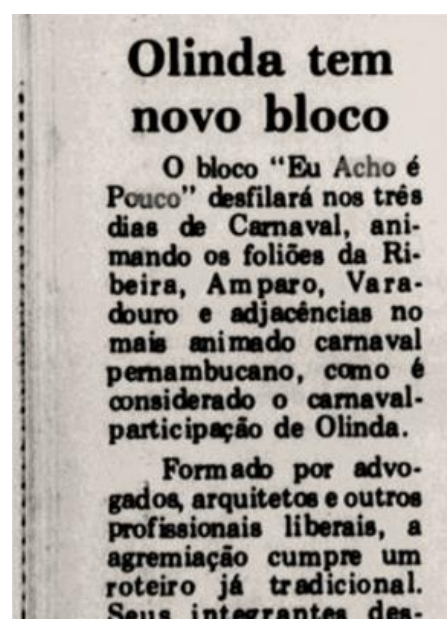

As primeiras notícias sobre o grêmio (figura 3) evidenciavam o desejo dos organizadores em uniformizar a brincadeira, 'querem apenas que os simpatizantes venham de amarelo e vermelho' (Diário de Pernambuco, 1981a). Na mesma década, também por inciativa de Roberto Lúcio, surgiram as primeiras camisas personalizadas. A estampa mais antiga que se tem registro visual é do ano de 1983 (figura 4), assinada por Neide Câmara e desenvolvida artesanalmente (Veras, 2019, p. 52).

Figura 4: Estampa de 1983 (Fonte: Veras, 2019).

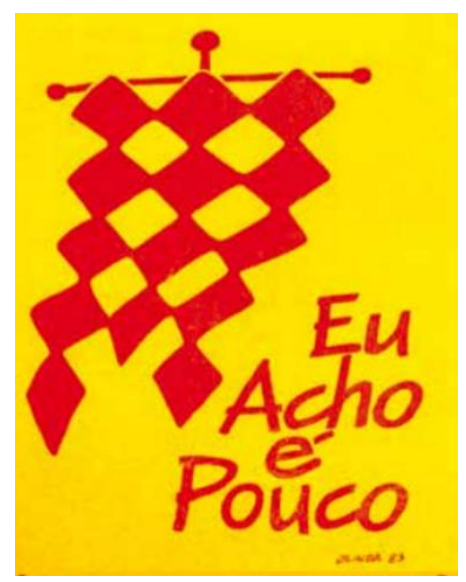

A crítica política não ficou restrita apenas ao discurso do Eu Acho é Pouco, a 'Constituinte Carnavalesca' (figura 5) reuniu blocos anti-establishment, a exemplo do Siri na Lata (responsável pela convenção), Segura a Coisa, Diu como te amo (de discurso feminista) entre outros (Diário de Pernambuco, 1981b). 
Figura 5: A crítica política no carnaval de Olinda em 1981 (Fonte: Diário de Pernambuco, acervo da biblioteca nacional).

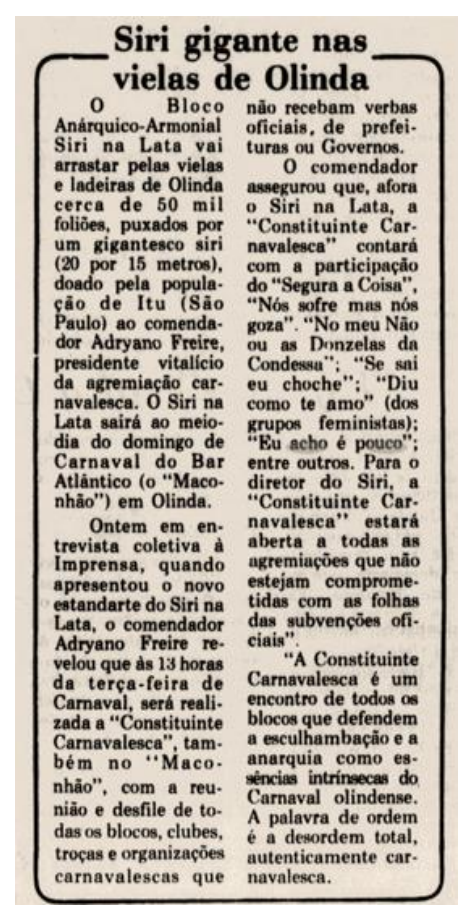

De 1983 até 1992, ao menos cinco estampas da agremiação fizeram críticas políticas evidentes, como por exemplo a de 1990, 'Apólice da Dívida Pública'. A peça imitava um documento imperial, com ornamentos, alegorias e tipografias características do século XIX. Nesse sentido, era esperado que o carnaval de 1993 fosse marcado pela crítica política, uma vez que em dezembro do ano anterior o país viveu a renúncia de Fernando Collor, meses após a inflação ter chegado a 80\% em 1990 (Fausto, 2015, p. 291). Por outro lado, conforme veremos adiante, a preocupação dos carnavalescos olindenses esteve ligada a preservação da cultura pernambucana.

Segundo Veras (2019), na década de 1990 o carnaval pernambucano começou a sofrer influências da música baiana e do norte. Em meio ao 'modismo' que três anos depois daria corpo ao Recifolia', o Eu Acho é Pouco, no polo oposto, se organizava como um militante em defesa do frevo. Segundo esta autora, uma notícia publicada pelo Jornal do comércio no dia 21 de fevereiro destacava o seguinte:

Todas as músicas tocadas durante o desfile são ritmos da terra, como os frevos de rua, de bloco e canção, além dos hinos das agremiações olindenses. 'Os novos ritmos e modismos, como a lambada, não farão parte do nosso repertório', afirma Antônio Chaves (um dos fundadores da agremiação)

(Jornal do Comercio, 1990 apud. Veras, 2019, p. 182).

Inclusive, em 1993 chegou a ser discutido um projeto de lei que estipulava uma cota de 60\% de frevo no repertório musical do carnaval de Olinda. Este projeto gerou polêmicas pela possibilidade de ser interpretado pela mídia nacional como um ato de censura, de igual modo que também limitava o consumo de outros ritmos do carnaval pernambucano, como por exemplo o maracatu (ibidem).

\section{Definindo as ferramentas}

\section{Twyman: a linguagem gráfica e a estrutura do contexto}

\footnotetext{
${ }^{2}$ Recifolia foi um evento do tipo 'carnaval fora de época' realizado no mês de outubro no bairro de Boa Viagem entre os anos 1993 e 2003.

Anais do 9ำ Congresso Internacional de Design da Informação | CIDI 2019

Proceedings of the 9th Information Design International Conference

Anais do $9^{\circ}$ Congresso Nacional de Iniciação Científica em Design da Informação | CONGIC 2019

Proceedings of the $9^{\text {th }}$ Information Design Student Conference
} 
Objetivando conciliar as duas perspectivas, da linguística e do design gráfico, acerca da tipologia fundamental da comunicação, Twyman (1982, p. 7) sugeriu que a linguagem deveria ser classificada primeiramente como auditiva e visual (não apenas entre falada e escrita). Utilizando como critério o canal de transmissão da mensagem, Twyman exibiu seu raciocínio conforme a figura 6 . A linguagem auditiva ficaria dividida entre verbal (falada) e não-verbal (sirenes, batidas, sons da natureza e etc.) e a linguagem visual, entre gráfica e não-gráfica.

Figura 6: Tentativa de acomodar as abordagens da linguística e do design gráfico (Fonte: Twyman, 1972, reprodução nossa).

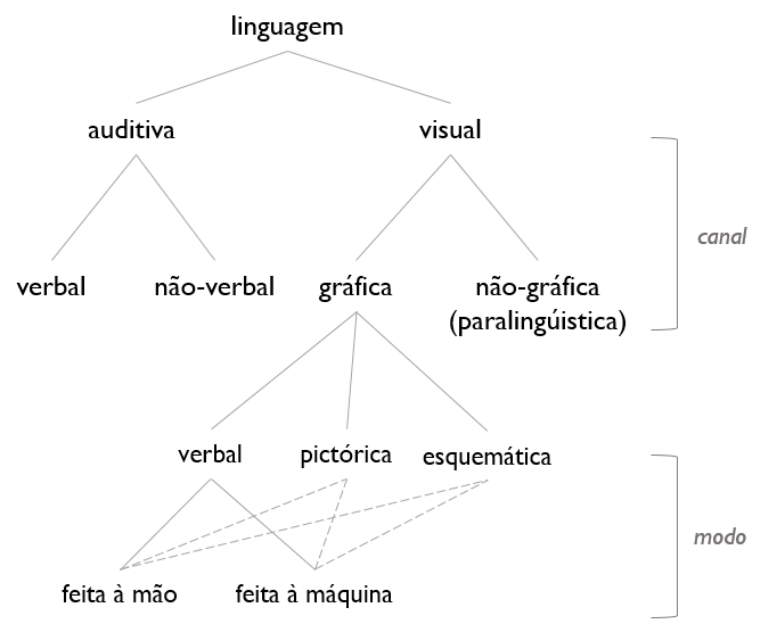

A linguagem visual não-gráfica, ou paralinguística englobaria, entre outras possíveis formas de comunicação, a gestual. A linguagem visual gráfica, por sua vez, ficaria dividida entre a verbal (a representação gráfica da linguagem falada), pictórica (a representação gráfica, abstrata ou objetiva, de algo real ou imaginado cuja referência pudesse ser compreendida pelo observador) e esquemática (formas gráficas que não fossem letras, números ou imagens pictóricas). Todas elas podendo ser produzidas manualmente ou mecanicamente. Em seu esquema, Twyman (1979) apresentou uma matriz taxonômica para análise das características da linguagem gráfica (figura 7). Neste sistema ele dispôs no eixo vertical os modos de simbolização e no eixo horizontal ele agrupou as maneiras de organização da informação no espaço.

Figura 7: A matriz de Twyman para o estudo da linguagem gráfica. Fonte: (Twyman, 1979, reprodução nossa).

\begin{tabular}{|c|c|c|c|c|c|c|c|}
\hline & linear puro & $\begin{array}{l}\text { linear } \\
\text { interrompido }\end{array}$ & | lista & $\begin{array}{l}\text { linear } \\
\text { ramificado }\end{array}$ & matriz & \begin{tabular}{|l} 
não-linear \\
dirigida
\end{tabular} & $\begin{array}{l}\text { nao-linear } \\
\text { aberto }\end{array}$ \\
\hline $\begin{array}{l}\text { verball } \\
\text { numericico }\end{array}$ & & & & & & & \\
\hline $\begin{array}{l}\text { pictónico } \\
\text { é verbal } \\
\text { numérico }\end{array}$ & & & & & & & \\
\hline pictorico & & & & & & & \\
\hline esquemático & & & & & & & \\
\hline
\end{tabular}

Toda comunicação (verbal ou não verbal) acontece num contexto de espaço, tempo e envolve atores (emissores e receptores), neste sentido, Twyman (1985, p. 248) considera que em qualquer situação onde a linguagem gráfica seja utilizada deveremos considerar, também, os fatores não gráficos relacionados a ela. Esse autor, portanto, oferece uma 'estrutura Anais do 9 Congresso Internacional de Design da Informação | CIDI 2019 Proceedings of the 9th Information Design International Conference

Anais do $9^{\circ}$ Congresso Nacional de Iniciação Científica em Design da Informação | CONGIC 2019

Proceedings of the $9^{\text {th }}$ Information Design Student Conference 
operacional' (ibidem) para que possamos compreender o contexto de produção de um artefato visual. Essa estrutura abrange os seguintes fatores: (1) propósito; (2) conteúdo informacional; (3) configuração; (4) modo; (5) meio de produção; (6) recursos; (7) usuários e (8) circunstâncias de uso.

\section{Mijksenaar e as variáveis gráficas}

A partir das variáveis gráficas apresentada por Jacques Bertin, Mijksenaar (1997) organizou um modelo (figura 8) em duas categorias de variáveis principais (diferenciadoras e hierárquicas) e uma categoria de apoio (as de suporte visual). O objetivo de Mijksenaar era oferecer aos designers um aporte mais direcionado aos projetos desenvolvidos pela classe, pois, segundo este autor, as variáveis de Bertin (por serem próprias da linguagem da cartografia) são originalmente apresentadas de maneira pouco funcional ao uso dos designers (Mijksenaar,1997).

As variáveis diferenciadoras, portanto, assinalam as diferenças pela categoria ou tipo, as hierárquicas assinalam as diferenças por importância, e finalmente as de suporte que funcionam como auxiliares, ou seja, enfatizando ou acentuando as informações visuais (Coutinho, 2011). Na primeira categoria ele inclui cores, imagens, largura de colunas e tipografia. Na segunda categoria, ele considera as variantes, sequência de leitura (pela disposição espacial), localização na página, tamanho e peso da tipografia, e os espaços entre linhas. E na terceira ele agrupa áreas de cor e sombreamento, linhas, caixas, símbolos, 'logos', ilustrações e atributos textuais (ex. itálico) (Mijksenaar, 1997, p. 38) (tradução nossa).

Figura 8: Variáveis gráficas de Mijksenaar (Fonte: Mijksenaar, 1997, reprodução nossa).

\begin{tabular}{ll}
\hline $\begin{array}{l}\text { Distinguishing } \\
\text { classifies according to category and } \\
\text { type }\end{array}$ & $\begin{array}{l}\text { color } \\
\text { Illustrations } \\
\text { column width } \\
\text { typeface }\end{array}$ \\
\hline $\begin{array}{l}\text { Hierarchical } \\
\text { classifies accordign to } \\
\text { importance }\end{array}$ & $\begin{array}{l}\text { sequential position (chronology) } \\
\text { position on the page (layout) } \\
\text { type size } \\
\text { type weight } \\
\text { line spacing }\end{array}$ \\
\hline Supporting & areas of color and shading \\
accentuating and emphaszing & lines and boxes \\
& symbols, logos, Illustrations \\
text atributes (italic, etc.)
\end{tabular}

Ao analisar os rótulos comerciais de cachaça em Pernambuco, Coutinho (2011), adaptou para o seu trabalho, o modelo de Mijksenaar. Um dos objetivos dessa pesquisadora era conhecer como o sistema informacional dos rótulos foi organizado, quais elementos indicavam importância, semelhanças e diferenças (a partir da hierarquia visual). Isto posto, também mantivemos as categorias e a estrutura da matriz proposta por Mijksenaar, apenas acrescentando outros itens específicos observados na análise das informações contidas na estampa, como por exemplo o 'lettering' referente ao nome do bloco.

\section{Ashwin: o sintático e o semântico nas imagens pictóricas}

Bertin (2010, p. 2) observou que em relação ao significado, as imagens podem ser do tipo monossêmica (que não permitem mais de uma interpretação), polissêmica (que permitem mais de uma interpretação) e pansêmica (que permitem infinitas interpretações) (tradução nossa). Ao considerar que qualquer afirmação sobre o significado relativo a estas duas últimas tipologias cairia no campo 'subjetivo' e consequentemente 'discutível', este autor circunscreve seu trabalho no domínio das imagens cartográficas (aderentes a condição monossêmica).

Para Ashwin, a maioria das ilustrações que entendemos como imagens pictóricas são monossêmicas (ex. ilustrações técnicas) e polissêmicas (a maioria das ilustrações artisticas). Para este autor, a condição panssêmica é pouco recorrente nas ilustrações artisticas, um vez que 'a significação primária da maioria das ilustrações contemporâneas é relativamente estável 
e não ambígua, na medida em que, nesse nível semântico elementar, muitas imagens parecem virtualmente monossêmicas' (Ashwin, 1979, p. 53, tradução nossa).

O pricipal argumento deste autor é que existem duas formas de analisar uma imagem pictórica: sintaticamente e semanticamente, mas que ambas se complementam, pois 'mudanças na sintaxe resultam em mudanças no 'significado' da imagem'(Ashwin, 1979, p. 55) (tradução nossa). Isso posto, as imagens pictóricas guardam um nível semântico elementar que permite interpretações mais ou menos estáveis e verificáveis, e que ao nível sintático as

'propriedades físicas da imagem podem ser consideradas independentemente de suas propriedades semânticas e operam como um importante contraponto ao conteúdo semântico, fornecendo-Ihe uma identidade gráfica que modifica significativamente o efeito da imagem sobre o observador' (ibidem) (tradução nossa).

Objetivando auxiliar os ilustradores, designers e diretores de arte a fazerem escolhas projetuais mais consientes em relação ao sentido que os seus projetos necessitam comunicar, Ashwin propôs sete ingredientes (presentes na maioria das ilustrações contemporâneas) articuláveis a partir de dois polos, a saber: (1) consistência (homogênea x heterogênea); (2) gama (contraído x expandido); (3) enquadramento (disjuntivo x conjuntivo); (4) posicionamento (simétrico $\mathrm{x}$ casual; (5) proximidade (perto $\mathrm{x}$ distente); (6) cinética (estática $\mathrm{x}$ dinâmica); (7) naturalismo (naturalista x não-naturalista) (Ashwin, 1979, pp. 57-67).

\section{Analisando o artefato}

No início da análise, constatamos que o próprio artefato ${ }^{3}$ já trazia muitas informações referentes aos tópicos de contexto sugeridos por Twyman como observado na figura 9 (lê-se: 'Desenhos originais de Bajado'). Com o auxílio de uma lupa também pudemos coletar outras informações sobre a identidade dos projetistas, o propósito da peça gráfica e o conteúdo informacional.

Figura 9: Coleta de dados sobre o contexto a partir das informações visuais (Fonte: Elaborada pelos autores no âmbito da pesquisa).

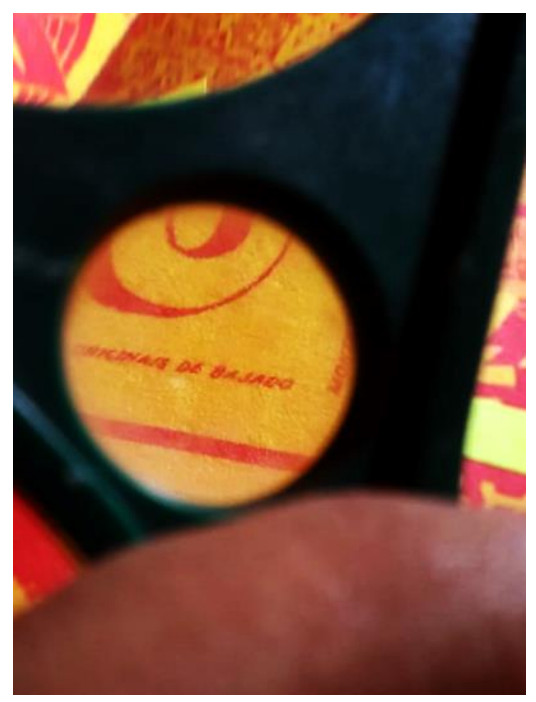

Sabendo que as referências visuais foram as pinturas do próprio Bajado (figura 10), fizemos uma busca no conjunto das pinturas que já haviam sido coletadas para a dissertação. Considerando a relevância do processo de criação do artefato para nosso estudo, desejávamos encontrar alguns personagens do repertório figurativo de Bajado por meio da comparação visual entre a estampa e os quadros.

\footnotetext{
${ }^{3}$ Não tivemos acesso a estampa em tamanho original, a reprodução analisada por nós mede $8 \times 6$ centímetros e foi impressa em papel polén bold $90 \mathrm{~g} / \mathrm{m}^{2}$.

Anais do 9o Congresso Internacional de Design da Informação । CIDI 2019

Proceedings of the 9th Information Design International Conference

Anais do $9^{\circ}$ Congresso Nacional de Iniciação Científica em Design da Informação | CONGIC 2019

Proceedings of the $9^{\text {th }}$ Information Design Student Conference
} 
Figuras 10 e 11: Pranchas comparativas entre as figuras da estampa com as pinturas de Bajado (Fonte: Veras, 2019 e Casa Bajado de Arte).
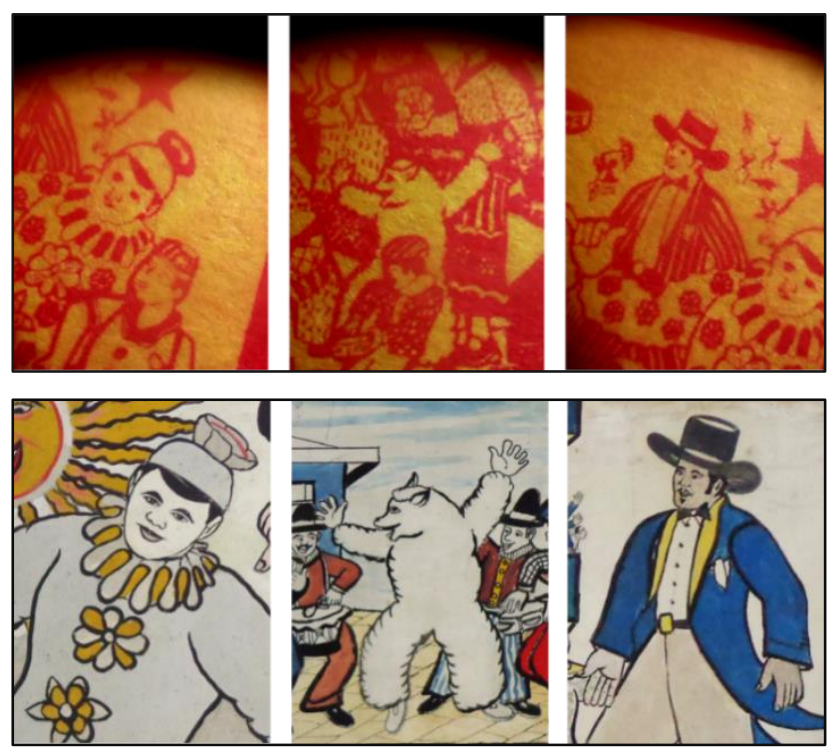

A figura 11 mostra os três personagens identificados na figura 10, o pierrô, o urso e o Homem da Meia Noite. Ao todo encontramos seis possíveis quadros de referência ${ }^{4}$ (todos pertencentes ao acervo da Casa Bajado de Arte, expostos permanentemente no Palácio dos Governadores, gabinete da prefeitura de Olinda) e treze personagens (figura 12).

Figura 12: Algumas possíveis referências para composição da estampa (Fonte: Elaborada pelos autores no âmbito da pesquisa).

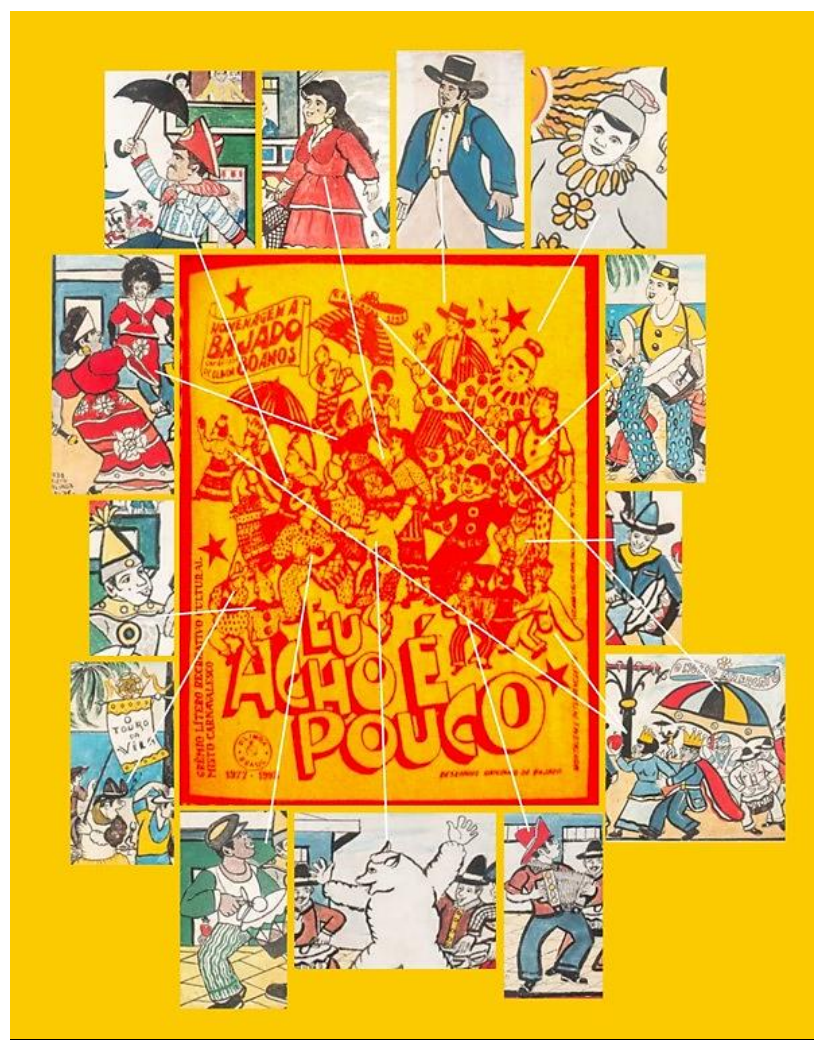

${ }^{4}$ Figuras 18 a 23.

Anais do 9ำ Congresso Internacional de Design da Informação । CIDI 2019

Proceedings of the 9th Information Design International Conference

Anais do $9^{\circ}$ Congresso Nacional de Iniciação Científica em Design da Informação | CONGIC 2019

Proceedings of the $9^{\text {th }}$ Information Design Student Conference 
A busca pelas referências visuais fez surgir a hipótese de que o lettering |Eu Acho é Pouco| pudesse ter sido inspirado em algum letreiramento desenhado por Bajado. Encontramos dois autorretratos do artista, um em Córdula (2013, p. 95) de 1977, muito divergente, e outro em Cuentro (1985, s. p.) de estilo muito semelhante ao observado na estampa (recortado da estampa e dessaturado digitalmente) (figura 13).

Figura 13: Comparação das letras de Bajado com o lettering da estampa (Fonte: Córdula, 2013); Cuentro (1985) e Veras, 2019).
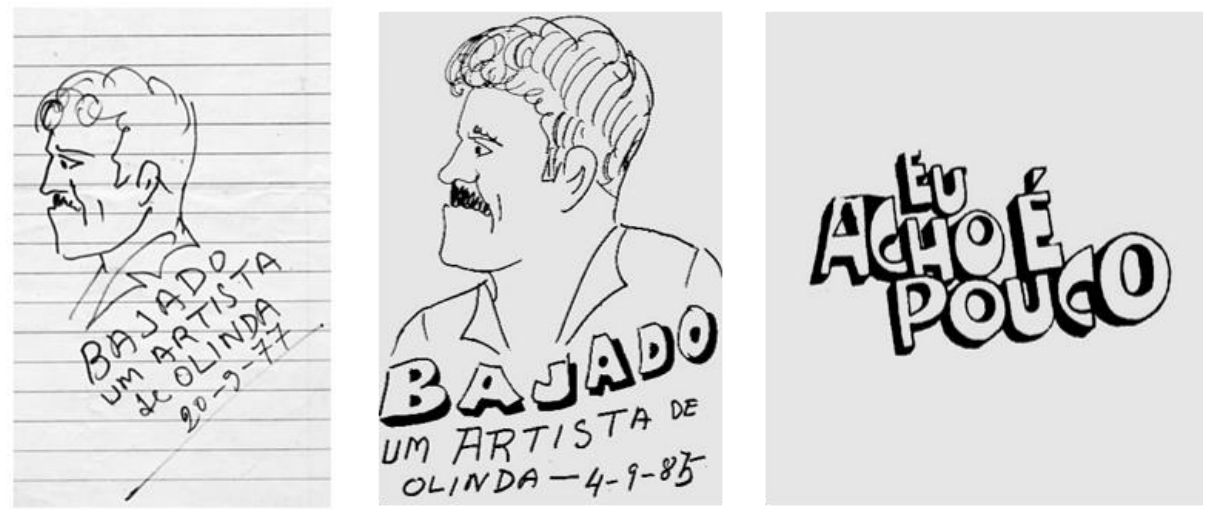

Segundo Veras (2019, p. 54), 'a partir de 1987, e até 1999, coube ao artista plástico e designer gráfico Petrônio Cunha a incumbência de criar as estampas das camisas'. Uma das principais características visuais deste profissional é o trabalho com recortes em papel e a hipótese de que a estampa de 1993 pudesse ter sido concebida por meio dessa técninca se confirmou. Primeiro as designers Luciana Calheiros e Paola Verri fizeram a coleta das ilustrações que foram decalcadas em papel manteiga. Em seguida o meterial foi repassado a Petrônio Cunha, que organizou a composição final junto às letras que havia recortado em papel.

Ao analisar o histórico das estampas do Eu Acho é Pouco pudemos observar que a semelhança do lettering com a letra de Bajado se deu mais pela insersão de profundidade nas letras do que pelo desenho delas, pois o estilo utilizado pela agremiação (figura 14) já tinha características sedimentadas. Para Veras (2019), assim como o dragão, o estilo de letra usado por Petrônio já era símbolo do bloco antes mesmo de 1993 (2019, p. 38).

Figura 14: Estampas em sequência 1992, 1993 e 1994 (Fonte: Veras, 2019).

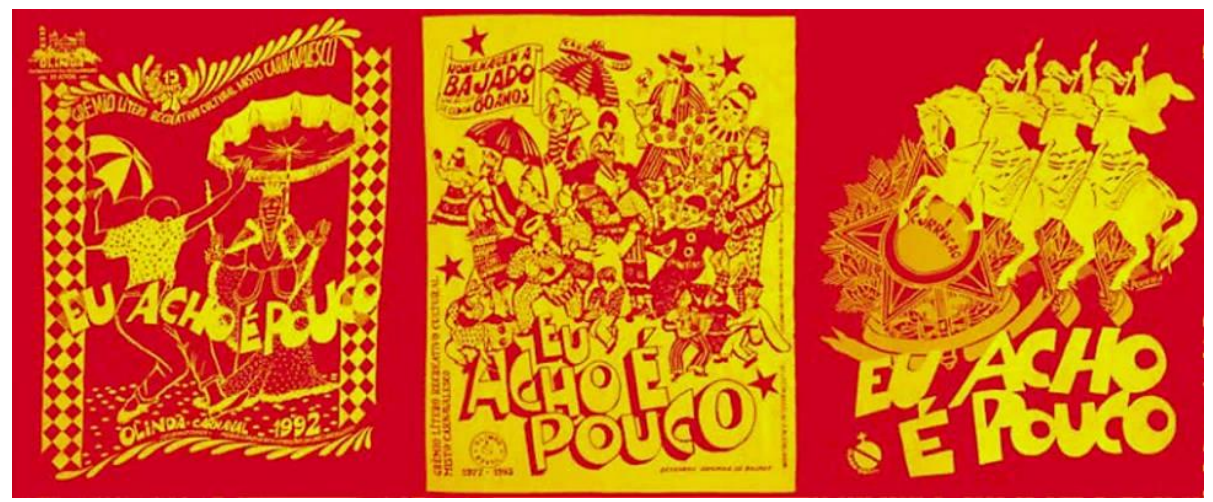

Quanto ao canal de transmissão da informação, a estampa do Eu Acho é Pouco é um artefato de linguagem visual gráfica e o seu modo de simbolização predominante é o pictórico, mas também se observa a utilização do modo verbal-numérico. A configuração geral da peça é não-linear aberta e sua produção pode ser considerada artesanal, as vistas que tanto a construção (decalques e recorte) como a reprodução (serigrafia) são técnicas manuais. Todas as informações relativas ao contexto foram organizadas na tabela 1. 
Tabela 1: Elementos do contexto de acordo com a proposta de Twyman.

\begin{tabular}{l|l} 
propósito & $\begin{array}{l}\text { Estamparia temática para o cortejo do Grêmio Lítero Cultural Recreativo } \\
\text { Misto Eu Acho é Pouco para o carnaval de 1993 }\end{array}$ \\
\hline $\begin{array}{l}\text { conteúdo } \\
\text { informacional }\end{array}$ & $\begin{array}{l}\text { Eu Acho é Pouco } \\
\text { Homenagem a Bajado | 80 Anos | Um artista de Olinda } \\
\text { Grêmio Lítero Recreativo Cultural Misto Carnavalesco } \\
\text { Olinda - Brasil | 1977-1993 } \\
\text { Desenhos originais de Bajado } \\
\text { Montagem e intervenções de: Luciana Calheiros, Paola Verri e Petrônio } \\
\text { Cunha }\end{array}$ \\
\hline configuração & Não-linear aberto \\
\hline modo & Pictórico e verbal-numérico \\
\hline meio de produção & $\begin{array}{l}\text { Concepção em recorte de papéis e reprodução em serigrafia (tinta amarela } \\
\text { sobre malha de algodão vermelha) }\end{array}$ \\
\hline recursos & Privado, fomentado pelos próprios organizadores do grêmio \\
\hline usuários & $\begin{array}{l}\text { Brincantes do bloco (familiares/amigos dos fundadores e pessoas } \\
\text { militantes/simpatizantes da esquerda política) }\end{array}$ \\
\hline circunstâncias de uso & Carnaval de rua, Olinda em 1993 \\
\hline
\end{tabular}

Neste sentido, cabe mencionar que duas das características mais marcantes das peças gráficas do Eu Acho é Pouco é o bi cromatismo a e utilização de planos chapados. Embora as cores do bloco sejam apenas amarelo e vermelho, é possível que a tecnologia da serigrafia, utilizada em todos os anos desde meados de 1980, possa ter influenciado na sedimentação de um 'estilo Eu Acho é Pouco' de comunicação visual, uma vez que não encontramos, inclusive atualmente, peças com degradês, sombreados, ou texturas.

Em termos de hierarquia (figura 15), observamos que ao primeiro nível de leitura o contraste de hierarquias foi atenuado pela articulação quase equilibrada entre os pesos visuais formados a partir da intensa mancha gráfica (provocada pela proximidade de muitas figuras menores) locada no eixo superior com o moderado peso visual (provocado pelo lettering vasado) disposto no eixo inferior. Esse efeito foi possível mais pela articulação entre as subcategorias hierárquicas de localização do que pela subcategoria hierárquica de tamanho.

Figura 15: Análise gráfica a partir das variáveis de Mijksenaar (Fonte: Elaborada pelos autores no âmbito da pesquisa).

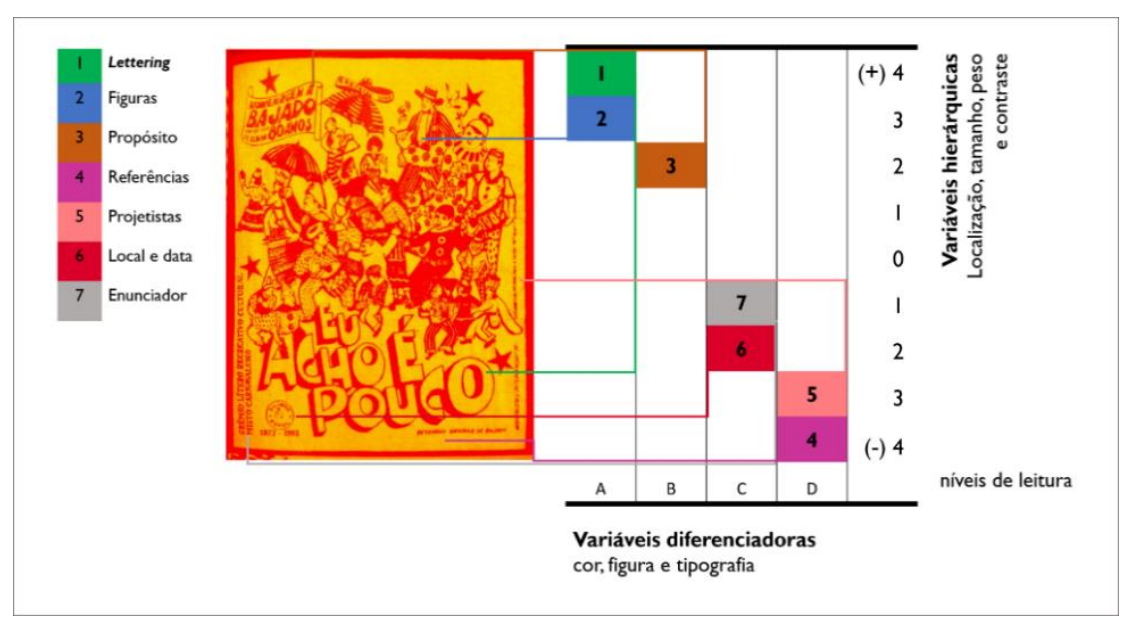

No primeiro nível de leitura $(A)$, observamos que as variáveis diferenciadoras tipografia e figura, embora separadas, têm seus limites justapostos formando um encaixe. Na letra |a| em |acho| existe uma pequena sobreposição da figura sobre o lettering. No segundo nível de leitura (B) se considerarmos que a função do listel nessa composição seja a de circunscrever informações importantes (o octogésimo aniversário do homenageado), perceberemos que este elemento funciona como uma variante da subcategoria de suporte visual 'caixa'. No terceiro nível de leitura $(C)$, também encontramos uma forma circular servindo para dar ênfase à informação referente ao local (figura 16). 
Figura 16: Vaiáveis de suporte utilizadas na estampa (Fonte: Veras, 2019).
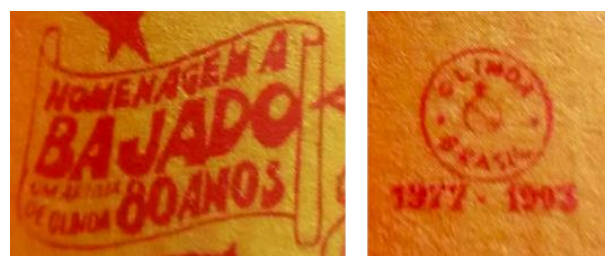

Pelas variáveis de Ashwin (figura 17), observamos que a consistência da estampa é heterogênea, além da utilização de tipografia e imagem, as técnicas empregadas foram recortes de papel e ilustração manual. Os planos chapados, que materializam o fundo e as figuras, assim como a não utilização de sombras ou muitos traços detalhistas, evidenciam que a gama é contraída.

Figura 17: Análise da estampa pelas categorias de Ashwin (Fonte: Elaborada pelos autores no âmbito da pesquisa).

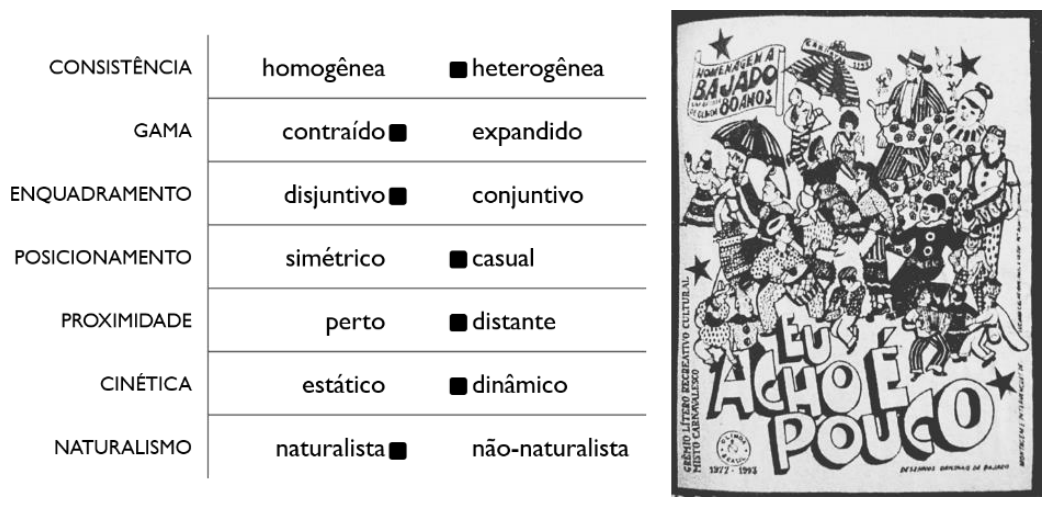

As obras de Bajado são notadamente enquadradas em planos gerais horizontais (como se fossem vistas acontecendo em um palco) (figuras 18 e 19), a estampa por outro lado, disposta na vertical induz a compreensão de que a reunião de personagens é observada de um plano superior. Pela sensação de completude, considerando que os elementos centralizados estão totalmente envolvidos pelo fundo, o enquadramento é disjuntivo.

Figura 18 e 19: Nosso Maracatu (1976) e Urso do Rosário de Olinda (1976) (Fonte: Casa Bajado de Arte).
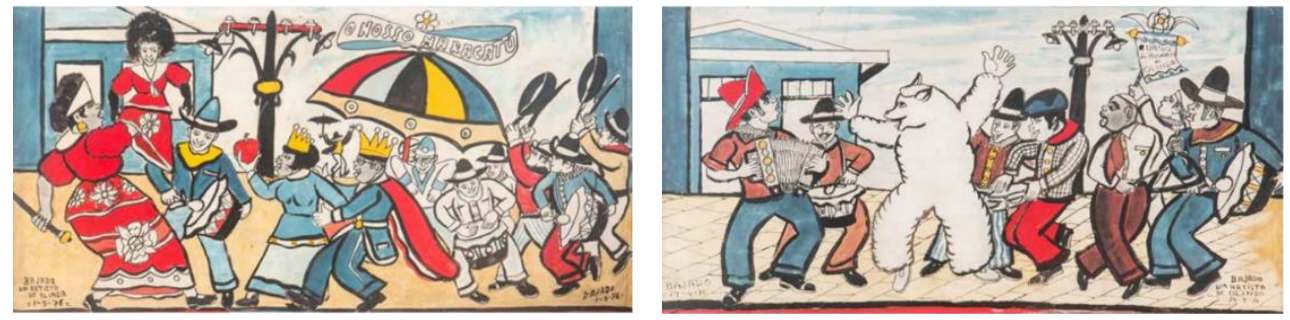

Assim como nas obras de Bajado (figura 20), o posicionamento dos elementos da estampa é casual e as pequenas figuras estão dispostas inclinadamente nos mais diversos ângulos. Outro ingrediente que também é comum no trabalho de Bajado e foi utilizado na estampa é a proximidade distante, pois na linguagem visual do artista não é verificada expressivamente a presença de closes $^{5}$, uma vez que ele preferia retratar suas cenas do ponto de vista externo (Prado, 1997).

\footnotetext{
${ }^{5}$ Das quarenta pinturas coletadas para a dissertação em apenas uma foi identificado o uso de close. Anais do 9ำ Congresso Internacional de Design da Informação | CIDI 2019 Proceedings of the 9th Information Design International Conference

Anais do $9^{\circ}$ Congresso Nacional de Iniciação Científica em Design da Informação | CONGIC 2019

Proceedings of the $9^{\text {th }}$ Information Design Student Conference
} 
Figura 20: O frevo é bom (1972) (Fonte: Casa Bajado de Arte).

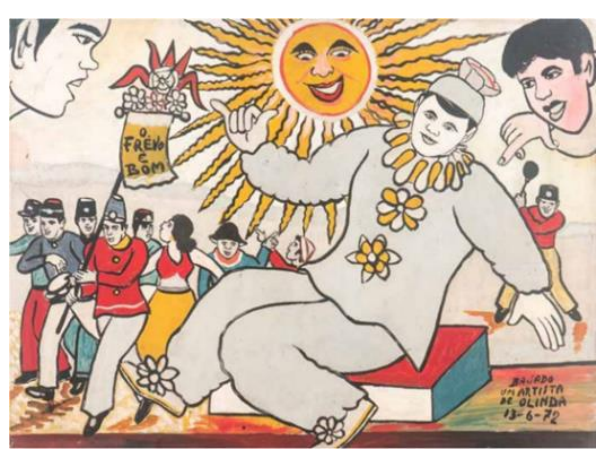

Uma das principais características do estilo de Bajado (figuras 21 e 22) é a cinética dinâmica. Seus personagens parecem dançar e andar como em um cortejo carnavalesco, este aspecto também é percebido na peça do grêmio. Interessante pontuar que o efeito cinético da obra de Bajado não é provocado pelo o uso das linhas de força ou outros grafismos (como nos quadrinhos), mas sim pela forma como ele posiciona os pontos de equilíbrio dos corpos dos seus personagens.

Figura 21 e 22: O Homem da Meia-Noite e Bajado (1980) e Carnaval em Olinda (A Mulher do Dia, Pitombeira, Elefante e Vassourinhas) (1980) (Fonte: Casa Bajado de Arte).
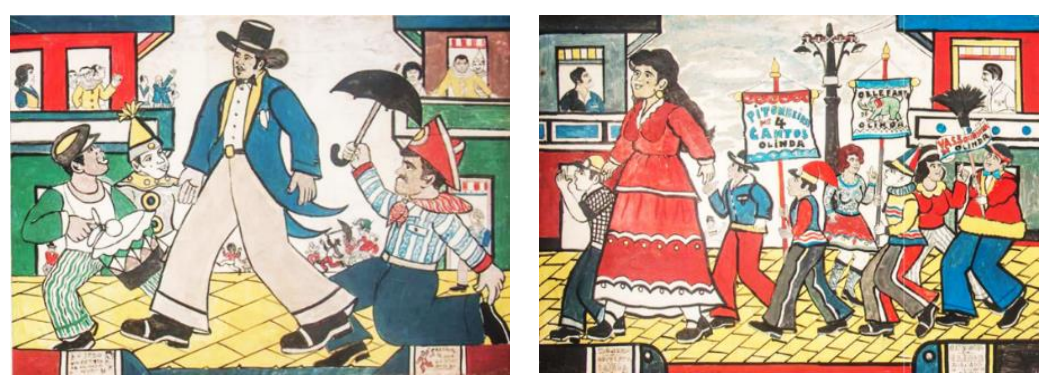

Se considerarmos que o naturalismo é dado pela relação com o mundo real (não avaliando as proporções e a fidelidade física do que está sendo representado e sim o que semanticamente está representado), a estampa pode ser considerada naturalista (uma vez que retrata uma reunião de personagens como se formassem uma multidão de foliões no carnaval de rua). Bajado pintava cenas do cotidiano (figura 23) e alguns dos seus personagens eram brincantes fantasiados, mas não fantasiosos (como as alegorias estudadas por Panofsky em seu estudo da iconografia $)^{6}$.

Figura 23: O Touro da Vila (1973) (Fonte: Casa Bajado de Arte).

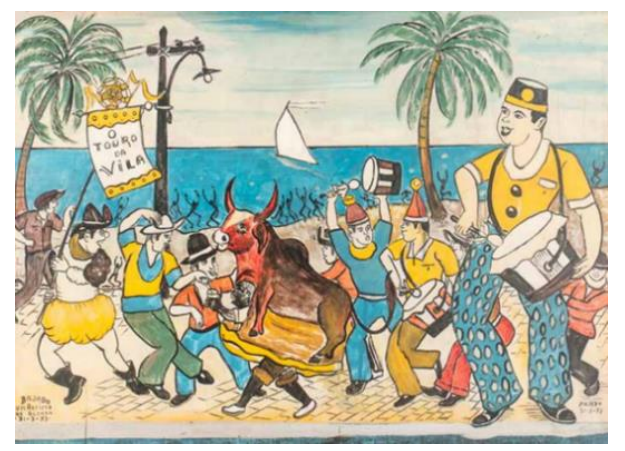

\footnotetext{
${ }^{6}$ PANOFSKY, Erwin. 2017. Significado nas artes visuais. Tradução Maria Clara F. Kneese e J. Guinsburg; - São Paulo: Perspectiva.
}

Anais do 9 Congresso Internacional de Design da Informação | CIDI 2019

Anais do $9^{\circ}$ Congresso Nacional de Iniciação Científica em Design da Informação | CONGIC 2019

Proceedings of the $9^{\text {th }}$ Information Design Student Conference 


\section{Inferências acerca da significação}

Assim como as diversas declarações afetivas feitas a cidade de Olinda (visualmente nos quadros e verbalmente nas entrevistas), informações gráfico-verbais de cunho regionalista como 'O frevo é bom' e 'Nosso Maracatu' (figuras 18 e 20) são recorrentes na obra de Bajado (Prado, 1997). 'O pintor de Olinda', como o próprio assinava as obras e se apresentava ao público, também costumava se auto retratar nos quadros (figura 24). $O$ artista também ficou conhecido pela irredutibilidade aos vários convites que recusou para morar fora de Pernambuco, sobretudo depois de ter seu trabalho noticiado pelo jornal francês Le Monde em 1973 e sempre dizia que jamais deixaria Olinda (Bajado, 1980; 1985).

Figura 24: Prancha comparativa entre a reprodução e a auto representação de Bajado.(Fonte: Veras, 2019 e Casa Bajado de Arte).
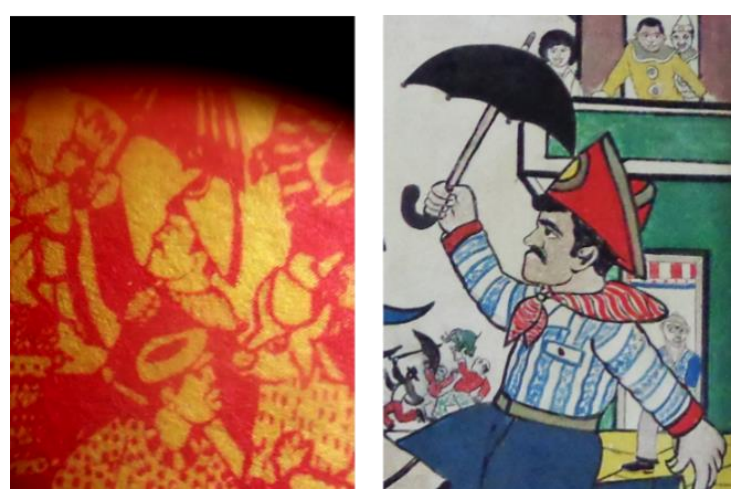

As articulações entre os elementos visuais sintetizaram os traços figurativos do trabalho de Bajado com as características, já sedimentadas, da identidade gráfica do Eu Acho é Pouco (planos chapados bicolores, estilo tipográfico e a estética serigráfica) de modo que hierarquicamente ambas grandezas apresentaram níveis equânimes de protagonismo na composição. Podemos inferir que a historicidade destes dois polos semânticos (político e regionalista do grêmio) / (afetivo e regionalista de Bajado) imprimiram à peça, sobretudo naquele contexto da interferência da música 'estrangeira', o discurso pró-frevo de caráter regionalista.

\section{Considerações finais}

Para Córdula (2013, p. 116) o carnaval é uma expressão coletiva e multifacetada, por isso 'é gráfico, plástico e simbólico'. Por meio de ferramentas do design da informação procuramos entender como a linguagem gráfica de um artefato visual intermediou a comunicação entre uma agremiação carnavalesca e seu público.

À luz das considerações de Twyman foi possível identificar pontos relevantes no entendimento do contexto em que o artefato esteve inserido, ao passo que as variáveis de Mijksenaar nos ajudaram a compreender como o discurso gráfico hierarquizou as grandezas sígnicas envolvidas no texto visual. Os ingredientes do estilo de Ashwin nos permitiram fazer inferências ao nível semântico sobre as possíveis relações de significação entre a linguagem gráfica do grêmio com a linguagem gráfica do homenageado.

\section{Agradecimento}

À Luciana Calheiros e Petrônio Cunha, pela afetividade, disponibilidade e gentileza.

\section{Referências}


Ashwin, C. (1979). The Ingredients of Style in Contemporary Illustration: A case study. In Information Design Journal, 1(1), pp. 51-67.

Calheiros, I. (2019). In VERAS, Luciana. Eu acho é pouco: o carnaval em vermelho e amareloRecife: Zoludesign.

Bertin, J. (2010). Semiology of Graphics. University of Wisconsin Press, Madison,Wisconsin.

Córdula, R. (2013). Olinda: Utopia do olhar. Recife : Fundarpe.

Coutinho, S. (2011). In: Imagens comerciais de Pernambuco: Ensaios sobre os efêmeros da Guaianases/ org. Silvio Barreto Campelo, Isabela Aragão. - Recife: Néctar.

Cuentro, J. (1985). Bajado, um artista de Olinda. - Olinda: Fundação centro de preservação dos sítios históricos de Olinda.

DIÁRIO DE PERNAMBUCO. 1981a. Recife, 22 fev. Carnaval, p.A-20. In: $<$ http://memoria.bn.br/hdb/periodico.aspx>, 11/04/2019.

DIÁRIO DE PERNAMBUCO. 1981b. Recife, 25 fev. Carnaval, p.A-11. In: $<$ http://memoria.bn.br/hdb/periodico.aspx>, 11/04/2019.

Farias, P., \& Braga, M. C. (2018). Dez ensaios sobre memória gráfica. - São Paulo: Blucher.

Fausto, B. (2015). História concisa do Brasil. - São Paulo: Editora da Universidade de São Paulo.

Lima G. C., Lima E. C., Barros, H., \& Lessa, W. D. (2016). Rótulos cromolitográficos brasileiros: efêmeros, memória gráfica, cultura material e identidade nacional. In:. Revista Brasileira de Design da Informação/Brazilian Journal of Information Design. São Paulo, 13(3), [2016], p. $199-213$.

Meneses, U. T. B. (2003). Fontes visuais, cultura visual, História visual. Balanço provisório, propostas cautelares. In: Revista Brasileira de História. São Paulo, 23(45), pp. 11-36.

Mijksenaar, P. (1997). Visual Function: An Introduction to Information Design. Princeton Architectural Press.

Prado, G. (1997). Bajado. - Recife: Cepe.

SECRETARIA DA SEGURANÇA PÚBLICA. 1972. In Relatório Brasil Nunca Mais, 710 processos do STM, Acervo do Conselho Mundial de Igrejas e Documentos da Comissão Justiça e Paz. In: <http://bnmdigital.mpf.mp.br/pt-br/>, 14/04/2019.

Twyman, M. (1979). A Schema for the Study of Graphic Language. KOLERS, P.A. \& WROSTAD, M.E. \& BOUMA, H. (Eds.), In: The Processing of Visible Language, vol. 1, Plenum, New York, pp. 117-150. 1979.

. 1982. The graphic presentation of language. In: Information Design Journal, 3/1,

pp. 2-22.

.1985. Using pictorial language: a discussion of the dimensions of the problem. In

T. M. Dufty and R. Waller (eds.) Designing usable texts. Orlando, Florida: Academic Press, p. 245-312.

Veras, L. (2019). Eu acho é pouco: o carnaval em vermelho e amarelo - Recife: Zoludesign.

Woodward, I. (2007). Understanding Material Culture. Londres: Sage Publications.

\section{Sobre o(a/s) autor(a/es)}

Rafael Santana, Mestrando, UFPE, Brasil <rafaelsantanna360@gmail.com>

Eva Rolim Miranda, Doutora, UFAL, Brasil <evarolim@gmail.com>

Anais do 9ำ Congresso Internacional de Design da Informação | CIDI 2019

Proceedings of the 9th Information Design International Conference

Anais do $9^{\circ}$ Congresso Nacional de Iniciação Científica em Design da Informação | CONGIC 2019

Proceedings of the $9^{\text {th }}$ Information Design Student Conference 